\title{
SABERES, LINGUAGENS E PRÁTICAS EDUCATIVAS: \\ OS VÉRTICES DE UM DIÁLOGO NECESSÁRIO \\ (O CASO DO ALANDROAL/PORTUGAL) ${ }^{1}$
}

Bravo Nico

Universidade de Évora/Portugal

\section{INTRODUÇÃO}

A relação entre os sistemas de qualificação e os territórios é uma realidade complexa e determinante para a adequada resolução da equação qualificadora em cada contexto territorial e respectivas dimensões sociais, económicas e culturais.

Aspectos como a geografia, a orografia, as acessibilidades ou o tipo de povoamento, entre outras, assumem-se, na actualidade, como variáveis importantes que devem ser consideradas nos processos de desenho e concretização das políticas de qualificação, principalmente nas que incorporam preocupações de estímulo ao desenvolvimento local.

O território comporta, entretanto, outras dimensões que se cruzam com a dimensão da qualificação e respectivas redes. De facto, em cada contexto geográfico, resultado da acção de um universo de instituições que nele existem ou actuam, podemos identificar outras redes territorializadas - com as suas linguagens e práticas educativas específicas - que concorrem para a qualificação dos indivíduos e das instituições (Nico, 2008).

A qualificação, em cada território - respectivas circunstâncias histórica, social, económica e cultural -, é um meio heterogéneo e dinâmico, onde coexistem múltiplas iniciativas e respectivos promotores, num mapa que, na maioria dos casos, não foi previamente desenhado nem tão-pouco pensado, mas que resultou de cada acção singular.

Observar, conhecer e, eventualmente, intervir, neste mapa da qualificação em cada território, é um exercício de enorme complexidade e exigência, que requer uma

\footnotetext{
${ }^{1}$ no âmbito do Projecto de Investigação PTDC/CED/81388/2006 "Arqueologia das Aprendizagens no Alandroal", promovido pelo Centro de Investigação em Educação e Psicologia da Universidade de Évora e financiado pela Fundação para a Ciência e a Tecnologia.
} 
leitura atenta, pormenorizada e integradora, do universo educacional da realidade e uma latitude conceptual suficientemente capaz de albergar a totalidade da diversidade de projectos qualificadores existente em cada contexto.

O caso que aqui é apresentado - concelho do Alandroal, sito na região Alentejo, ao sul de Portugal - oferece-nos um quadro bastante interessante de análise desta complexa relação que existe entre o território e a qualificação.

\section{AS REDES DE QUALIFICAÇÃO}

\subsection{AS REDES FORMAIS DE QUALIFICAÇÃO}

O Alandroal é um município com 544,86Km2 de área e aproximadamente 6100 habitantes (INE, 2002). É integrada por seis freguesias: Juromenha, Terena, São Brás dos Matos, Capelins, Santiago Maior e Nossa Senhora da Conceição.

No território do concelho do Alandroal, verificamos a coexistência de quatro redes formais de qualificação, que, em seguida, indicaremos.

\subsubsection{A rede formal de educação}

Nesta primeira dimensão, encontramos as seguintes realidades:

i) a Intervenção Precoce - modalidade de intervenção que se destina a crianças até à idade escolar que estejam em risco de atraso de desenvolvimento, manifestem deficiência, ou necessidades educativas especiais. Consiste na prestação de serviços educativos, terapêuticos e sociais a estas crianças e às suas famílias com o objectivo de minimizar efeitos nefastos ao seu desenvolvimento. A tutela deste programa é repartida entre os Ministérios da Saúde, da Educação e do Trabalho e Solidariedade Social;

ii) os estabelecimentos de Educação Pré-Escolar - constituem uma rede onde coexistem instituições públicas, privadas e solidárias. Estes estabelecimentos são tutelados pelas respectivas instituições proprietárias e encontram-se enquadrados por normativos dos Ministérios da Educação e do Trabalho e da Solidariedade; 
iii) a Escola Pública, no âmbito dos Ensinos Básico e Secundário, no território do município do Alandroal e em municípios adjacentes constituída pelos estabelecimentos de ensino públicos que disponibilizam a oferta educativa, ao nível dos ensinos básico e secundário. A tutela desta rede compete ao Ministério da Educação, sendo que a Câmara Municipal do Alandroal possui competências no âmbito do ensino básico, nomeadamente no que se refere aos edifícios, funcionários não-docentes, actividades de enriquecimento curricular, transportes escolares, alimentação e outro tipo de apoios;

iv) as Escolas Privadas nos territórios próximos do município do Alandroal - constituída pelos estabelecimentos de ensino privados e cooperativos que disponibilizam oferta educativa, ao nível do ensino secundário. Estas instituições são tuteladas pelos respectivos proprietários e pelo Ministério da Educação;

v) a rede de Centros Novas Oportunidades (CNO) - constituída pelos CNO públicos e privados que operam no município e em territórios próximos e que disponibilizam oferta educativa a adultos, nomeadamente através do processo de reconhecimento, validação e certificação académica e/ou profissional dos adquiridos experienciais (níveis básico e secundário) e do encaminhamento dos indivíduos para percursos de formação. A rede de CNO é tutelada pelos Ministérios da Educação e do Trabalho e Solidariedade Social.

\subsubsection{A rede formal de formação}

Nesta segunda dimensão, encontramos a formação profissional promovida pelos Centros de Formação Profissional do Instituto do Emprego e Formação Profissional que operam no território e que são tutelados pelo Ministério do Trabalho e da Solidariedade Social. 


\subsubsection{A rede formal do ensino superior}

Nesta terceira dimensão, encontramos a presença, activa, da acção de instituições públicas de ensino superior localizadas na região (Universidade de Évora e os Institutos Superiores Politécnicos de Beja e de Portalegre) e da Universidade Aberta (instituição pública de ensino superior a distância). Estas instituições são tuteladas pelo Ministério da Ciência, da Tecnologia e do Ensino Superior.

\subsubsection{A rede formal de qualificação}

A rede formal de qualificação é constituída pelas organizações não governamentais da sociedade civil que, tendo celebrado protocolos com o instituições públicas financiadoras, disponibilizam oferta qualificante certificada. É o caso de fundações, instituições particulares de solidariedade social, associações de desenvolvimento local, associações juvenis, empresas e outras. Estas instituições são tuteladas pelos respectivos associados e pelas organizações públicas financiadoras.

\subsection{AS REDES NÃO-FORMAIS DE QUALIFICAÇÃO}

No território do concelho do Alandroal, verificamos a coexistência de sete redes não-formais de qualificação, que, em seguida, indicaremos.

\subsubsection{A rede não-formal de aprendizagem}

Constituída pelas organizações não governamentais da sociedade civil que disponibilizam oferta qualificante não certificada. Para lá das instituições já indicadas anteriormente (cf. 1.4), poderão ainda incluir-se as associações de natureza desportiva, cultural e recreativa. Este universo de instituições é uma presença bastante activa no território, conta com uma participação significativa dos cidadãos e são tuteladas pelos respectivos associados.

\subsubsection{A rede não-formal de formação profissional}

Nesta dimensão, encontramos o universo de micro, pequenas e médias empresas locais, no seio das quais vão ocorrendo micro episódios de aprendizagem que proprietários e colaboradores vão concretizando. A aquisição de novos 
equipamentos, a adopção de novas estratégias de funcionamento, a contratação de novos colaboradores, a necessidade de cumprimento de novas regras contabilísticas ou organizacionais ou a necessidade de certificação dos produtos ou serviços disponibilizados são momentos em que ocorrem aprendizagens, a maioria das vezes não certificadas. Estas instituições são tuteladas pelos respectivos proprietários e, em determinadas circunstâncias, observam as indicações dos Ministérios da Economia, do Trabalho e da Solidariedade e das Finanças.

\subsubsection{A rede não-formal das instituições da dimensão social}

Neste âmbito, encontramos as organizações não-governamentais que desenvolvem actividades de apoio às comunidades locais, respectivas famílias e indivíduos. Este universo de instituições, com forte presença no território e importante acção social, são tuteladas pelos respectivos associados e cumprem, em determinadas circunstâncias, as indicações do Ministério do Trabalho e da Solidariedade e dos organismos municipais.

\subsubsection{A rede não-formal das instituições da dimensão cultural}

Nesta dimensão, desenvolvem actividade as instituições que promovem, divulgam e concretizam a actividade cultural. Estas organizações são tuteladas pelos respectivos associados e, em determinados casos, poderão celebrar protocolos com o Ministério da Cultura e com as autarquias locais.

\subsubsection{A rede não-formal das instituições de saúde}

Encontramos, neste plano, o Centro de Saúde e respectivas Extensões, a Farmácia e todas as organizações que, de forma directa ou indirecta, promovem actividades de aprendizagem não-formal, na área da saúde. Estas instituições são tuteladas pelo Ministério da Saúde.

\subsubsection{A rede não-formal das instituições de segurança}

No território em causa, encontramos a presença da Guarda Nacional Republicana que desenvolve acções de educação destinadas aos mais jovens, através do Programa Escola Segura, e aos mais idosos, através de programas de informação e 
prevenção. A Guarda Nacional Republicana é tutelada pelo Ministério da Administração Interna.

\subsubsection{A rede não-formal da comunicação social}

Constituída pelos órgãos de comunicação social locais e regionais, com actividade no território. Encontram-se nestas condições alguns jornais e rádios locais e regionais. Estas empresas são tuteladas pelos respectivos proprietários.

\subsection{AS REDES INFORMAIS DE QUALIFICAÇÃO}

No território do concelho do Alandroal, existe, ainda, uma décima segunda rede de qualificação: a rede informal, que se materializa nas redes comunitárias de convívio e de vizinhança que são, na região do Alentejo - caracterizada pelo povoamento concentrado, pela grande frequência de contactos sociais e pela força dos laços sociais e familiares - uma realidade muito importante no quotidiano de cada indivíduo.

\section{ALGUMAS COORDENADAS DO MAPA DA QUALIFICAÇÃO}

Deste exercício de cartografia educacional, ficamos perante uma realidade bem mais rica e interessante do que aquela que nos é proporcionada quando a nossa observação é filtrada pelas lentes da educação formal.

De facto, podemos concluir da existência de 12 redes de aprendizagem no território em estudo e de, pelo menos, outras tantas tutelas. Esta realidade, heterogénea, diversa e atomizada, remete-nos para a existência de vários pensamentos educacionais, diferentes saberes em contexto de aprendizagem e múltiplas práticas educativas, sendo certo que a maioria dos indivíduos frequenta, em simultâneo, muitos destes contextos de educação e formação.

Na tentativa de organizar, de forma simples, a informação anteriormente indicada, apresentamos, em seguida, uma categorização das principais características dos saberes, linguagens e práticas educativas que se encontram presentes nas redes formais e não-formais de educação existentes no território do município do Alandroal. 
Tabela 1. Características dos saberes, linguagens e práticas educativas

\begin{tabular}{|l|l|l|}
\hline & \multicolumn{1}{|c|}{ Redes Formais } & \multicolumn{1}{c|}{ Redes não-Formais } \\
\hline Saberes & $\begin{array}{l}\text { Académicos } \\
\text { Padronizados } \\
\text { Legitimados } \\
\text { Escritos } \\
\text { Hegemónicos }\end{array}$ & $\begin{array}{l}\text { Não académicos } \\
\text { Pouco formalizados } \\
\text { Locais } \\
\text { Pouco ou nada escritos } \\
\text { Em “perigo de extinção" }\end{array}$ \\
\hline Linguagens & $\begin{array}{l}\text { Científica } \\
\text { Escritas }\end{array}$ & $\begin{array}{l}\text { Empíricas } \\
\text { Pouco escritas ou orais }\end{array}$ \\
\hline Práticas Educativas & $\begin{array}{l}\text { Intrageracionais } \\
\text { Mais verticalizadas } \\
\text { Formalizadas } \\
\text { Monodimensionais }\end{array}$ & $\begin{array}{l}\text { Intra e intergeracionais } \\
\text { Menos verticalizadas } \\
\text { Conviviais } \\
\text { Multidimensionais }\end{array}$ \\
\hline
\end{tabular}

Outro aspecto a considerar, neste mapa da qualificação, decorre da existência de evidentes segmentações dos espaços e dos tempos da aprendizagem:

a) A segmentação geracional dos contextos de aprendizagem: decorre do predomínio dos indivíduos mais jovens nos contextos mais formais de qualificação, enquanto se verifica o inverso com os indivíduos menos jovens que frequentam mais os contextos não-formais. Esta dimensão promove um predomínio do contacto intrageracional e uma rarefacção dos contactos intergeracionais, facto que ainda é mais reforçado pelos diferentes espaços e tempos das rotinas pessoais e profissionais que os indivíduos adoptam, ao longo dos respectivos ciclos vitais;

b) A segmentação geracional na exposição aos saberes: o aumento dos percursos formais de aprendizagem, por parte das gerações mais jovens, tem sido acompanhado por uma maior exposição a saberes, linguagens e práticas educativas mais escolares e padronizadas. Ao contrário, as gerações menos jovens estão mais expostas aos saberes, linguagens e práticas educativas menos escolares e menos padronizadas, mais localizadas nos contextos familiares e comunitários; 


\section{c) A ausência de diálogo entre os saberes e linguagens que coexistem no}

território: esta realidade decorre da ausência dos saberes, linguagens e práticas educativas nos contextos formais e escolares de aprendizagem e do aumento, constante e progressivo, da distância entre as culturas locais $e$ escolares;

d) Um relacionamento interinstitucional casuístico e incoerente: que resulta do carácter atomizado e descoordenado da aç̧ão educacional, que promove, em determinadas circunstâncias, em sobreposição e competição.

\section{ALGUMAS COORDENADAS PARA UM NOVO MAPA DA QUALIFICAÇÃO}

Os resultados da cartografia que foi realizada no território do município do Alandroal (e que não será muito diferente do que existirá em todos os municípios portugueses) remetem-nos para um novo horizonte da realidade da qualificação nos territórios, onde identificamos novas coordenadas que determinam novas latitudes nos conceitos, nos pensamentos, nas práticas e nas decisões:

i) Alargamento do perímetro do conceito de instituição educativa, no sentido de, nessa nova geometria, se incluir a totalidade do universo institucional de cada território, no qual ocorre um conjunto diverso e rico de oportunidades de aprendizagem;

ii) Assumir a geometria variável e evolutiva da rede territorial de aprendizagem;

iii) Instituir um pensamento não-hegemónico que permita a simbiose entre a aprendizagem formal e as práticas educativas próprias dos contextos não-formais e a convivência e complementaridade entre as instituições das redes públicas de qualificação e as organizações da sociedade civil das comunidades locais; 
iv) Não perder a memória das comunidades e dos territórios, a qual, muitas vezes, só existe em plataformas culturais pouco organizadas e muito afastadas dos sistemas formais, escritos e legitimados de expressão;

v) Não excluir as comunidades e os respectivos territórios dos processos de desenho, construção e operacionalização dos sistemas formais de qualificação.

\section{CONCLUSÃO}

O diálogo entre os sistemas de qualificação e os territórios deve ter, como principal farol, a promoção de dinâmicas de desenvolvimento e de coesão social e, nessas condições, pensar a qualificação, num determinado território, convida-nos a um diálogo entre múltiplos aspectos de uma realidade complexa, diversa e heterogénea. Um diálogo entre saberes, linguagens e práticas educativas de diferentes origens, diversas modalidades de divulgação, distintas formas de legitimação e representações peculiares, por parte dos indivíduos, famílias, instituições e comunidades. Mas, também, um diálogo activo no âmbito de uma plêiade de actores locais que coexistem e se relacionam nos mesmos espaço e tempo.

É nesta nova latitude conceptual que devemos observar, estudar e intervir na realidade da qualificação em cada território, em concreto. Considerar todas as manifestações e episódios de aprendizagem, incluir todos os seus promotores e atribuir a mesma dignidade e valor a toda a qualificação, independentemente da sua origem ou características, é um novo exercício territorial que se torna necessário promover.

Cada alandroalense transporta, no seu portefólio pessoal de aprendizagem e de vida, o complexo contributo deste universo. Nenhum desses fragmentos é dispensável e todos têm o seu valor intrínseco. Se assim é, na vida de cada pessoa, assim deverá ser na realidade de cada território. 


\section{Referências Bibliográficas}

INE (2002). Censos 2001. Resultados definitivos. Lisboa: INE

NICO, B. (2008). "Aprender no interior português: vértices para um pensamento integrado e uma acção responsável". in Bravo Nico (Org.) Aprendizagens do Interior: reflexões e fragmentos. Lisboa: Edições Pedago. pp: 9-19 